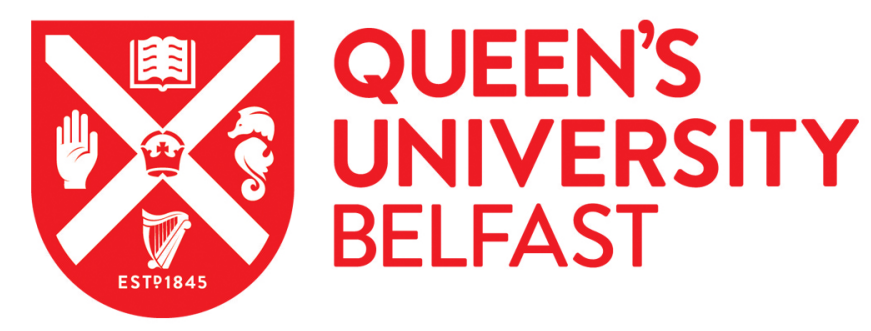

\title{
Effects of acute and chronic temperature changes on the functional responses of the dogfish Scyliorhinus canicula (Linnaeus, 1758) towards amphipod prey Echinogammarus marinus (Leach, 1815)
}

South, J., \& Dick, J. T. A. (2017). Effects of acute and chronic temperature changes on the functional responses of the dogfish Scyliorhinus canicula (Linnaeus, 1758) towards amphipod prey Echinogammarus marinus (Leach, 1815). Environmental Biology of Fishes, 1-13. https://doi.org/10.1007/s10641-017-0640-z

\section{Published in:}

Environmental Biology of Fishes

\section{Document Version:}

Publisher's PDF, also known as Version of record

Queen's University Belfast - Research Portal:

Link to publication record in Queen's University Belfast Research Portal

\section{Publisher rights}

Copyright 2017 the authors.

This is an open access article published under a Creative Commons Attribution License (https://creativecommons.org/licenses/by/4.0/), which permits unrestricted use, distribution and reproduction in any medium, provided the author and source are cited.

\section{General rights}

Copyright for the publications made accessible via the Queen's University Belfast Research Portal is retained by the author(s) and / or other copyright owners and it is a condition of accessing these publications that users recognise and abide by the legal requirements associated with these rights.

Take down policy

The Research Portal is Queen's institutional repository that provides access to Queen's research output. Every effort has been made to ensure that content in the Research Portal does not infringe any person's rights, or applicable UK laws. If you discover content in the

Research Portal that you believe breaches copyright or violates any law, please contact openaccess@qub.ac.uk. 


\title{
Effects of acute and chronic temperature changes on the functional responses of the dogfish Scyliorhinus canicula (Linnaeus, 1758) towards amphipod prey Echinogammarus marinus (Leach, 1815)
}

\author{
Josie South $(\mathbb{D})$ Jaimie T. A. Dick
}

Received: 26 January 2017 / Accepted: 18 July 2017

(C) The Author(s) 2017. This article is an open access publication

\begin{abstract}
Predation is a strong driver of population dynamics and community structure and it is essential to reliably quantify and predict predation impacts on prey populations in a changing thermal landscape. Here, we used comparative functional response analyses to assess how predator-prey interactions between dogfish and invertebrate prey change under different warming scenarios. The Functional Response Type, attack rate, handling time and maximum feeding rate estimates were calculated for Scyliorhinus canicula preying upon Echinogammarus marinus under temperatures of $11.3{ }^{\circ} \mathrm{C}$ and $16.3{ }^{\circ} \mathrm{C}$, which represent both the potential daily variation and predicted higher summer temperatures within Strangford Lough, N. Ireland. A two x two design of "Predator Acclimated", "Prey Acclimated", "Both Acclimated", and "Both Unacclimated" was implemented to test functional responses to temperature rise. Attack rate was higher at $11.3^{\circ} \mathrm{C}$ than at $16.3{ }^{\circ} \mathrm{C}$, but handling time was lower and maximum feeding rates were higher at $16.3{ }^{\circ} \mathrm{C}$. Non-acclimated predators had similar maximum feeding rate towards nonacclimated and acclimated prey, whereas acclimated predators had significantly higher maximum feeding rates towards acclimated prey as compared to nonacclimated prey. Results suggests that the predator attack rate is decreased by increasing temperature but
\end{abstract}

J. South $(\bowtie) \cdot$ J. T. A. Dick

Institute for Global Food Security, School of Biological Sciences, Queen's University Belfast, MBC, 97 Lisburn Road, Belfast,

Northern Ireland, UK

e-mail: josiesouth93@gmail.com when both predator and prey are acclimated the shorter handling times considerably increase predator impact. The functional response of the fish changed from Type II to Type III with an increase in temperature, except when only the prey were acclimated. This change from population destabilizing Type II to more stabilizing Type III could confer protection to prey at low densities but increase the maximum feeding rate by Scyliorhinus canicula in the future. However, predator movement between different thermal regimes may maintain a Type II response, albeit with a lower maximum feeding rate. This has implications for the way the increasing population Scyliorhinus canicula in the Irish Sea may exploit valuable fisheries stocks in the future.

Keywords Thermal responses - Functional response . Feeding ecology $\cdot$ Climate change

\section{Introduction}

Temperature is a driver of interspecific interactions through mediating metabolism (Arrhenius 1889; Brown et al. 2004) and therefore locomotion (Dell et al. 2011; Dell et al. 2014), attack speed (Nowicki et al. 2012), feeding rates (Iacarella et al. 2015), and growth (Savage et al. 2004; Pörtner and Knust 2007). Therefore, temperature has a direct effect upon energy flux through an ecosystem and the population dynamics within it (Woodward et al. 2010; Stevnbak et al. 2012; Cahill et al. 2013). Thermal responses are understood to be an underlying mechanism behind predator - prey 
dynamics (Berlow et al. 2009; Rall et al. 2010; Englund et al. 2011), but predicting the outcome of such interactions under future abiotic scenarios is highly problematic (Le Quesne and Pinnegar 2011). This is partly due to multiple layers of real world complexities such as habitat heterogeneity (MacNeil et al. 2004; Ferner et al. 2009; Alexander et al. 2015; Barrios-O’Neill et al. 2015), light (Koski and Johnson 2002), multiple predator effects (Lang et al. 2012; Alexander et al. 2013; Wasserman et al. 2016a). The apparent species specificity of thermal dynamics poses an additional layer of difficulty in response prediction due to the metabolism of different species having varying sensitivity to temperature effects and therefore producing differential responses (Lang et al. 2012). It is thus difficult to derive accurate conclusions from thermal responses modeled across numerous systems (Grigaltchik et al. 2012), but it is widely agreed that temperature change alters ecological stability (Dell et al. 2014; Gilbert et al. 2014).

Predicting future responses to warming temperatures is complex due to systems being multifaceted in their response to temperature change. The effects of temperature change can be discernable on an individual level (Huey et al. 1999; Calosi et al. 2013; Vasseur et al. 2014), and on population and community levels (Le Quesne and Pinnegar 2011; Rall et al. 2012). Furthermore, thermal change may manifest as long-term chronic temperature increase or as acute temperature variations over short periods of time (Vasseur et al. 2014). While chronic warming allows time for adaption to a higher temperature, short-term temperature variation exposes organisms rapidly to potentially adverse conditions. Both scenarios are caused by ongoing climate change (Easterling et al. 1997, 2000) and can affect the life history and fitness of organisms (Yocom and Edsall 1974; Biro et al. 2010; Terblanche et al. 2010; ClusellaTrullas et al. 2011).

Prediction of consumer impact has been assessed through the use of comparative functional response analyses (Smout et al. 2010; Alexander et al. 2012; Alexander et al. 2013; Dick et al. 2013; Dick et al. 2014; Laverty et al. 2014; Wasserman et al. 2016a, b; Dick et al. 2017). This method has been pioneered for the prediction of invasive species impacts in comparison to trophically analogous native species (Dick et al. 2013; Paterson et al. 2015; Dick et al. 2017). It is particularly useful in assessing ecological impact under a number of abiotic contexts (e.g. Alexander et al. 2015). Functional response refers to the rate of consumption of a resource with regards to resource density (Solomon 1949; Holling 1959). It is clear that species with a higher functional response (e.g., higher attack rates, lower handling times, higher asymptote) have a higher impact potential (Bollache et al. 2008; Haddaway et al. 2012; Dick et al. 2013). Functional responses are categorised into: the Type I rectilinear response, usually only found in filter feeders where resource consumption is not limited by handling time (Jeschke et al. 2004); the Type II inversely density dependent response with high prey consumption at low densities; and Type III sigmoidal, positively density dependent response whereupon prey have a low-density refuge (Oaten and Murdoch 1975). Within these response types, it is also possible to quantify the associated parameters of attack rate, handling time and maximum feeding rates (Juliano 2001; Dick et al. 2013). Functional response analysis therefore presents itself as a robust assessment method whereupon ecological impact can be explained and predicted across numerous biotic and abiotic contexts (Dick et al. 2014; Dick et al. 2017).

Warming oceans have the potential to alter interaction strengths between valuable commercial and noncommercial fisheries (Le Quesne and Pinnegar 2011). This has implications for maintaining biodiversity and economic value. As such there should be an emphasis on predicting and understanding the potential changes in species ecology under such climatic scenarios. This will pave the way for integrating results into management techniques well in advance so as to attempt to mititgate adverse change in community ecology and interaction strengths. We investigated predation by juvenile Scyliorhinus canicula (lesser-spotted dogfish) on amphipod prey Echinogammarus marinus. Both species are ubiquitous in temperate waters (Ellis and Shackley 1997; Duffy and Harvilicz 2001), resilient (Múrias et al. 1996; Revill et al. 2005; Leite et al. 2014) and pliable laboratory species (Sims 2003). These are ecologically relevant species as E. marinus has large impacts upon community structuring (Duffy and Hay 2000; Dick et al. 2005), and is an important prey species (Leite et al. 2014) that can additionally be considered a proxy for other small crustacean species and small fish due to strong swimming behaviours. $S$. canicula is a generalist benthic predator (Kaiser and Spencer 1994; Domi et al. 2005) with high abundances (Genner et al. 2010; Sguotti et al. 2016) that have been found to increase with increasing temperature (Sguotti et al. 2016). S. canicula presents as an ideal indicator species that is not affected by fishing 
mortality, due to lack of fishing pressure and high discard survival rate (Revill et al. 2005).

The present study presents the functional responses of juvenile Scyliorhinus canicula preying on live Echinogammarus marinus under the ambient temperature of $11 \pm 0.09{ }^{\circ} \mathrm{C}$ and attempts to elucidate whether there is a change in the functional response when temperature is increased to $16.3 \pm 0.20^{\circ} \mathrm{C}$, a value chosen as it is in line with future Sea Surface Temperature (SST) increase predictions (Sokolov et al. 2009). Furthermore, we attempted to use comparative functional responses to understand whether predator or prey was more profoundly affected by the temperature increase. A $2 \times 2$ factorial design was employed wherein both predator and prey were acclimated, just the predator was acclimated, just the prey were acclimated, and both predator and prey were unacclimated to $16.3{ }^{\circ} \mathrm{C}$. This takes into account the effect of increased temperature on resource consumption and the movement of predators between different thermal regimes (Sims et al. 2001) in an attempt to predict possible changes in predator-prey interaction strength in the future.

\section{Methods}

Thirty captive bred juvenile Scyliorhinus canicula (34.82 $\pm 2.77 \mathrm{SD}$ cm total length) were kept in three holding tanks $(120 \times 60 \times 60 \mathrm{~cm})$ at Queen's Marine Laboratory (QML Portaferry) and maintained on chopped mussel and mackerel ad lib. Three times a week. Trials were carried out from May-June 2016. The holding tanks were supplied with $11^{\circ} \mathrm{C}$ UV filtered seawater pumped directly from Strangford Lough, Northern Ireland. Echinogammarus marinus were collected by searching under cobbles on 'Walter's Shore', Portaferry. These were kept in aerated $28 \mathrm{~L}$ boxes. E. marinus was fed with Laminaria digitata which was replaced once a week.

Experimental setup involved three leader tanks $(120 \times 60 \times 60 \mathrm{~cm})$ heated with aquarium heaters. Three flow-through systems provided seawater into the leader tank to be heated, the water then flowed from the leader tank into six $60 \mathrm{~L}$ arenas. Airlines were fed directly into each leader tank to avoid confounds of low dissolved oxygen concentration (kept above 70\% saturation DO). Acclimation to the desired temperature took place over three days as temperature was increased from ambient to $16.3{ }^{\circ} \mathrm{C}$ at a rate of $2{ }^{\circ} \mathrm{C}$ every two days, and then a further two days at $16.3{ }^{\circ} \mathrm{C}$. Ten lesser-spotted dogfish were kept in each leader tank during acclimation. Echinogammarus marinus were acclimated in 28-1 boxes via the flow through system. The dogfish were fed ad lib. Throughout this time to avoid hyperphagy (Wootton and Ali 2001; Ali et al. 2003). Once the desired temperature was achieved, the water was held at $16.3 \pm 0.20{ }^{\circ} \mathrm{C}$. The mean summer temperature in Strangford Lough is $15.5^{\circ} \mathrm{C}$ (AFBI 2016). The raised temperature value reflects the potential daily variation in the summer and the $3-5{ }^{\circ} \mathrm{C}$ global (SST) increase predicted in the coming century (Sokolov et al. 2009).

A $2 \times 2$ experiment design was implemented wherein Factor 1 was "Predator Treatment" with respect to nonacclimation/acclimation to increased temperature and Factor 2 was "Prey Treatment" with respect to nonacclimation/acclimation to increased temperature. Therefore, treatments were: "Predator Acclimated" (prey unacclimated), "Prey Acclimated" (predator unacclimated), "Both Acclimated", "Both Unacclimated". An "Ambient" temperature treatment at $11 \pm 0.09{ }^{\circ} \mathrm{C}$ was included to get a baseline comparison. This was the temperature of Strangford Lough during the trial period, it represents the current spring average (AFBI 2016). This was preferred to a winter average due to the very low temperatures in winter slowing feeding behaviour in preliminary trials. Lesser-spotted dogfish were selected at random, measured and placed in arenas an hour before the trials started. Recovery time was short as the specimens were captive bred and somewhat used to handling. Densities of prey were supplied at 1, 3, 5, $10,15,20$ ( $n=4$ per density); prey size was $\sim 5-$ $10 \mathrm{~mm}$. Trials lasted for $2 \mathrm{~h}$ and the number of prey consumed were recorded at the end of this time by an observer. Individual fish were then placed in ambient temperature holding tanks for a week before reuse, no fish was reused in the same treatment or at the same prey density to avoid pseudo-replication. Amphipods were kept in experimental arenas in the absence of predators at each density treatment ( $n=3$ per density).

\section{Statistical analyses}

Data were non-parametrically bootstrapped $(n=30)$ to calculate multiple estimates of attack rate, handling time and maximum feeding rate. Welch's t-test was used to test differences in bootstrapped parameters between "Ambient" and "Both acclimated" (i.e. "raised') groups. Generalised linear models (GLM) with quasi- 
Poisson error distribution to account for over dispersion in the model were used to test for differences in functional response parameters [attack rate $(a)$, handling time $(h)$, and maximum feeding rate $(1 / h \mathrm{~T})]$ with respect to two factors; "Predator Treatment" and "Prey Treatment". Tukey honest significant difference posthoc tests were used for multiple pairwise comparisons.

Functional response analyses were carried out in $\mathrm{R}$ v.3.3.0 (R Development Core Team 2015). The R package 'frair' (Pritchard 2014; Pritchard et al. 2017) was used to model the functional response Type of Scyliorhinus canicula preying on Echinogammarus marinus. Functional response Type (I, II, III) was determined using a logistic regression of the proportion of prey consumed against prey density. If the proportion of prey consumed decreases with increasing prey density, then the logistic regression will produce a significantly negative first order term and thus the functional response Type will be classed as Type II (Juliano 2001). If the logistic regression produced an non-significant first order term, a GLM was run on the proportional data, in this case a Type II response would be signified by a significantly negative first order term followed by a significantly positive second order term (Juliano 2001), while a Type III is signified by a significantly positive first order term and significantly negative second order term (Juliano 2001). A Type I functional response could be determined from a non-significant first or second order term, however a Type I is categorical only in filter feeders or systems that meet the requirements stated in Jeschke et al. (2004). Therefore, when non-significant terms were encountered, a scatterplot with locally weighted scatterplot smoothing (LOWESS) lines, with a smoothing factor of $9 / 10$, were fitted to assess the direction of proportional consumption. This was used to assess the shape of proportional consumption of prey at different prey densities (Pritchard et al. 2017).

When a Type II response was indicated, the functional responses were modeled using Rogers' (1972) Random Predator Equation, due to the prey not being replaced as they were consumed (Juliano 2001):

$N_{e}=N_{o}\left(1-\exp \left(a\left(N_{e} h-T\right)\right)\right)$

where $N_{e}$ is the number of prey eaten, $N_{0}$ is the initial density of prey, $a$ is the attack rate, $h$ is the handling time and $T$ is the total time available. The Lambert $\mathrm{W}$ function was implemented to fit the model to the data (Bolker 2008).
When Type III functional responses were indicated, Hassell's Type III response was modeled to the data wherein $a$ is a hyperbolic function of $N_{o}$ (Juliano 2001), where $b, c$ and $d$ are constants and prey are depleted:

$N_{e}=N_{o}\left\{1-\exp \left[\left(d+b N_{o}\right)\left(h N_{e}-T\right) /\left(1+c N_{o}\right)\right]\right\}$

Flexible models were also modeled on the data as categorical Type II functional responses are $q=0$ and, as $q>0$, the functional response becomes proportionally more sigmoid, with $q=1$ indicating a Type III response. Treatments with GLMs indicating Type III were also modeled with a flexible model with $q$ fixed at 1 and Type II were modeled with $q$ fixed at 0 . The flexible model is an alteration of Rogers' Random Predator Equation (Eq. 1) with the addition of a scaling exponent $q$ (Real 1977; Vucic-Pestic et al. 2010).

$N_{e}=N_{0}\left(1-\exp \left(b N_{o}^{q}\left(h N_{e}-T\right)\right)\right)$

where $N_{e}$ is the number of prey consumed, $N_{o}$ is the initial prey density, $b$ is the search coefficient, $h$ is handling time, $q$ is the scaling coefficient, and $T$ is the total time available. The search coefficient in Eq. 3, $b$ combines with $N_{o}$ and $q$ to produce attack rates that vary with prey density, (i.e. $a=b N_{o}^{q}$ ) unlike in Eq. 1 where attack rate is fixed at all prey densities $\left(N_{o}\right)$.

Suitability of each model was compared with Akaike Information Criterion (AIC). Functional responses were then fitted using maximum likelihood estimation (MLE; Bolker 2010) and the Lambert W function (Bolker 2008).

\section{Results}

Control group prey survival was $>99 \%$ and thus prey mortality was assumed to be due to predation in the experimental groups. Attack rate was significantly higher at ambient $(0.92 \pm 0.05 \mathrm{SE})$ than raised temperature $(0.10$ $\pm 0.010 \mathrm{SE})(t=13.82, \mathrm{df}=30.59, p<0.001)$. Handling time was significantly shorter at raised temperature $(0.06$ $\pm 0.008 \mathrm{SE})$ compared to ambient $(0.10 \pm 0.008 \mathrm{SE})$ $(t=4.18, \mathrm{df}=51.03, p<0.001)$. This translated into a significantly higher maximum feeding estimate at raised temperature $(29.42 \pm 4.23 \mathrm{SE})$ compared to ambient $(12.37 \pm 1.67 \mathrm{SE})(t=3.74, \mathrm{df}=30.91, p<0.001)$.

Attack rate had a significant "predator treatment" $\mathrm{x}$ "prey treatment" interaction effect $\left(\mathrm{F}_{1,102}=98.69\right.$, $p<0.001$; Fig. 1). Wherein, predators that were nonacclimated showed higher attack rates to prey that were 
Fig. 1 Mean \pm SE of bootstrapped attack rate $(a)$ showing the interaction of predator and prey treatments

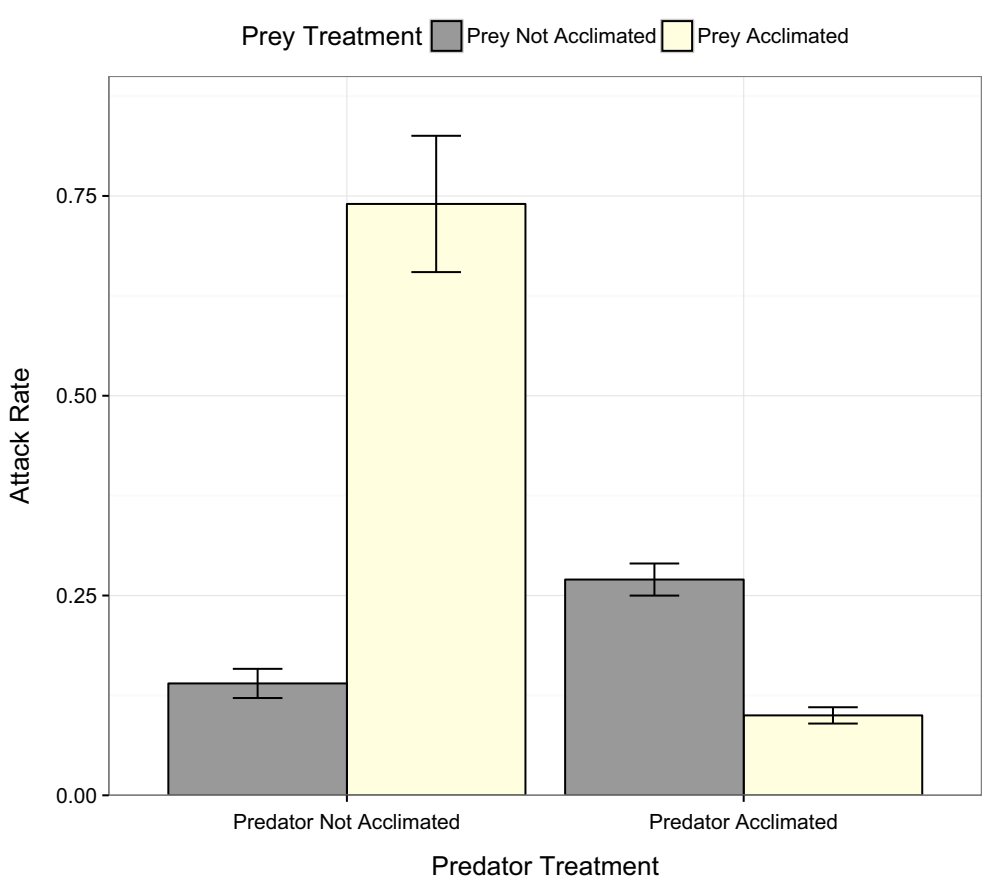

acclimated as compared to prey that were non-acclimated, whereas predators that were acclimated showed higher attack rates toward non-acclimated as compared to acclimated prey (Fig. 1).

Handling time had a significant "predator treatment" $\mathrm{x}$ "prey treatment" interaction effect $\left(\mathrm{F}_{1,102}=32.14\right.$, $p<0.001$; Fig. 2). That is, predators that were nonacclimated showed higher handling time to prey that were acclimated as opposed to non-acclimated, and predators that were acclimated showed higher handling times to prey that were non-acclimated as opposed to acclimated (Fig. 2).

Maximum feeding rate had a significant "predator treatment" $\mathrm{x}$ "prey treatment" interaction effect $\left(\mathrm{F}_{1}\right.$, $102=17.75, p<0.00$; Fig. 3). When predators were nonacclimated the maximum feeding rate was similar towards prey that were non-acclimated and prey that were acclimated, whereas when predators were acclimated the maximum feeding rate was higher towards prey that were acclimated as compared to non-acclimated prey (Fig. 3).

At ambient temperature $\left(11^{\circ} \mathrm{C}\right)$, the predator showed a Type II functional response (Table 1, Fig. 4). When just the predator was acclimated to $16.3^{\circ} \mathrm{C}$, there was no statistically significant Type III functional response, indicating that in this treatment there is a boundary Type I/ Type III response. Therefore, while fitting the model of a Type I response at the densities investigates, it was modeled as a Type III (Jeschke et al. 2004) (Table 1, Fig. 4). When both predator and prey were acclimated to $16.3^{\circ} \mathrm{C}$ a Type III response was fitted to the data (Table 1, Fig. 4). This had the highest maximum feeding rate estimate. When just the prey was acclimated there was a Type II functional response (Table 1, Fig. 4). When both predator and prey were unacclimated to $16.3{ }^{\circ} \mathrm{C}$ there was an non-significant Type III functional response which, again, was instead modeled as a Type III as suggested by the shape of the GLM (Table 1, Fig. 4). This has the lowest maximum feeding rate estimate. In both instances where there was an non-significant logistic regression and GLM, locally weighted scatterplot smoothing was used on the proportion of prey consumed per density to investigate the shape of the response (Fig. 5). It should be considered here that the handling times reported for predator acclimated and both unacclimated are unreliable due to the Type I response generated at the prey densities investigated.

\section{Discussion}

Prediction of the ecological ramifications of facets of climate change is particularly difficult due to inherent confounds of interactions between dissolved oxygen concentration and temperature (Peck et al. 2009; Grigaltchik 
Fig. 2 Mean \pm SE of bootstrapped handling time $(h)$ showing the interaction of predator and prey treatments

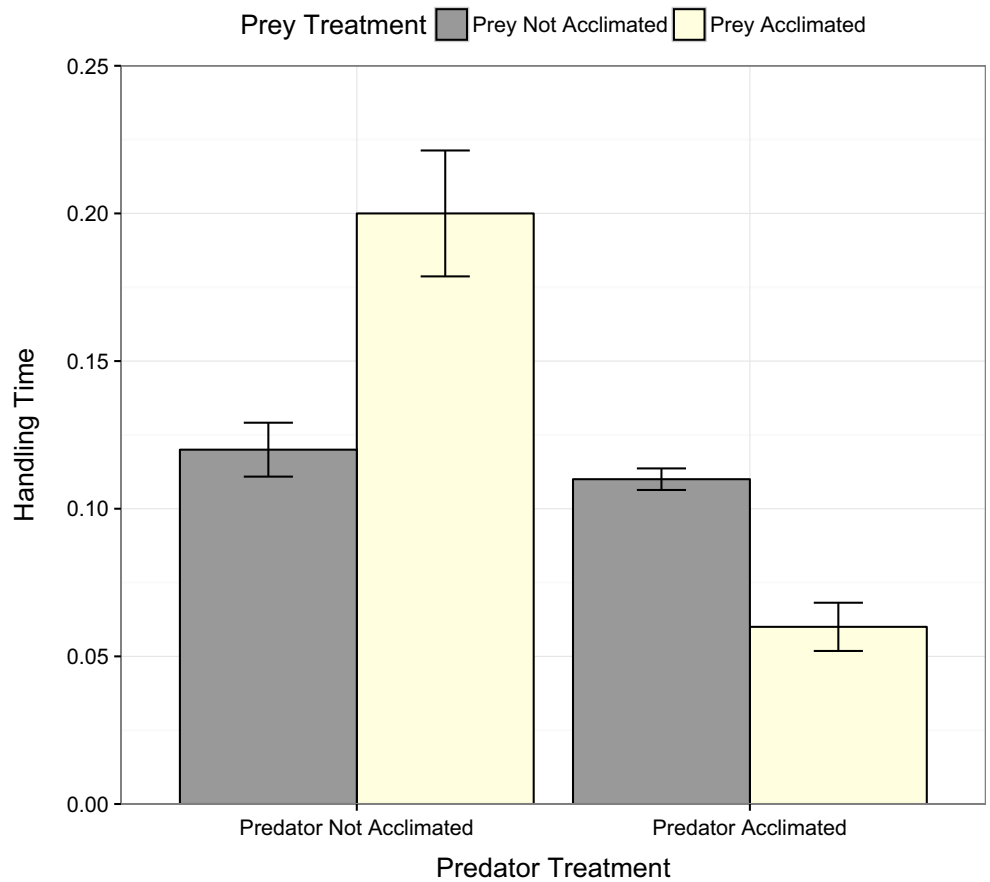

et al. 2012) and multi-species systems (Broitman et al. 2009). However, here we have shown that by using comparative functional response analyses, in a similar way to invasive species impact predictions (Dick et al. 2014; Wasserman et al. 2016b), it is possible to identify the impact of a predator under various warming scenarios and assess whether there are interaction effects when both sides of the predator-prey dynamic are considered.

Temperature increase mediated changes to the parameters associated with the functional response. There was a significantly higher attack rate when at "Ambient" temperature compared to "Both Predator
Fig. 3 Mean \pm SE of bootstrapped maximum feeding estimate $(1 / h \mathrm{~T})$ showing the interaction of predator and prey treatments

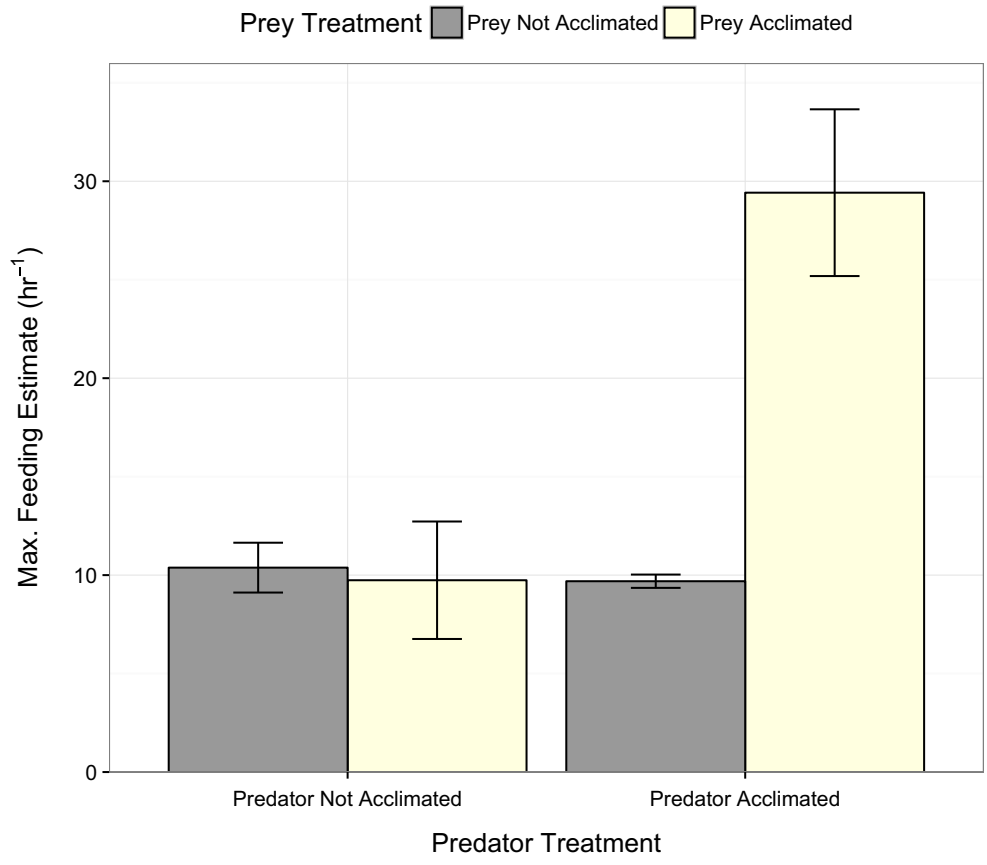


Table 1 Logistic regression first order terms, GLM first and second order terms with associated $p$ values and Functional Response Type for all experimental treatments

\begin{tabular}{lllll}
\hline Treatment & $\begin{array}{l}\text { (Log. Reg.) First order } \\
\text { term, }(p)\end{array}$ & $\begin{array}{l}(\text { GLM) First order } \\
\text { term, }(p)\end{array}$ & $\begin{array}{l}\text { (GLM) Second order } \\
\text { term }(p)\end{array}$ & $\begin{array}{l}\text { Functional } \\
\text { Response type }\end{array}$ \\
\hline Ambient & $-0.053,(<0.05)$ & $-0.133,(0.25)$ & $0.003,(0.47)$ & II \\
Predator acclimated & $-0.024,(0.30)$ & $0.164,(0.14)$ & $-0.007,(0.08)$ & III \\
Both acclimated & $0.087,(<0.001)$ & $-0.127(<0.001)$ & $0.008,(0.05)$ & III \\
Prey acclimated & $-0.025,(0.33)$ & $-0.365,(<0.01)$ & $0.014,(<0.01)$ & II \\
Both unacclimated & $0.008,(0.74)$ & $0.071,(0.54)$ & $-0.002,(0.58)$ & III \\
\hline
\end{tabular}

and Prey Acclimated" to $16.3{ }^{\circ} \mathrm{C}$. This contrasts with the meta-analysis by Rall et al. (2012) and the assumption that attack rate is temperature invariant (Dell et al. 2014), but is similar to results in Grigaltchik et al. (2012), wherein there was a decreased attack rate but a high predation pressure at increased temperature. Further, our results are similar to Wasserman et al. (2016b), wherein attack rate was highest in the lowest temperature at zero habitat complexity. Furthermore, attack rate considers both predator and prey responses thus, at a lower temperature, swimming speed may be decreased in the smaller bodied prey species and therefore make them easier to attack as they must use more energy to escape (Dell et al. 2011; Dell et al. 2014). As a consequence, the attack rate of the predator may be higher at lower temperature due to a change in attack success as a result of prey escape energy. The handling time was significantly shorter at the higher temperature and therefore the maximum feeding rate estimates were significantly higher at the higher temperature.
Temperature directly affects poikilotherm metabolism and has a somewhat bell shaped relationship with maximum consumption (Englund et al. 2011). At ambient temperature, dogfish take 2-3 days to fully digest a meal due to the slower rate of chemical reactions at low body temperature (Van Slyke and White 1911), thus the increase in digestion rate is comprehensible at a higher temperature (Gilbert et al. 2014). Juvenile lesser-spotted dogfish have almost double the metabolism rate of adult specimens (Sims 1996), so despite the short trial time, the predator may experience more motivational states during the raised temperature treatments due to the increased rate of digestion. This may alter searching behaviour at high prey densities (Clark and Mangel 2000; Ariyomo and Watt 2015). The behaviours that make up handling time are considered to be composite of a multitude of processes including; subduing, chewing, swallowing, digestion and gut evacuation, all of which are controlled by physiological processes that are affected in different manners by
Fig. 4 Functional response curves of Scyliorhinus canicula on Echinogammarus marinus for all treatments with standard error bars from raw data

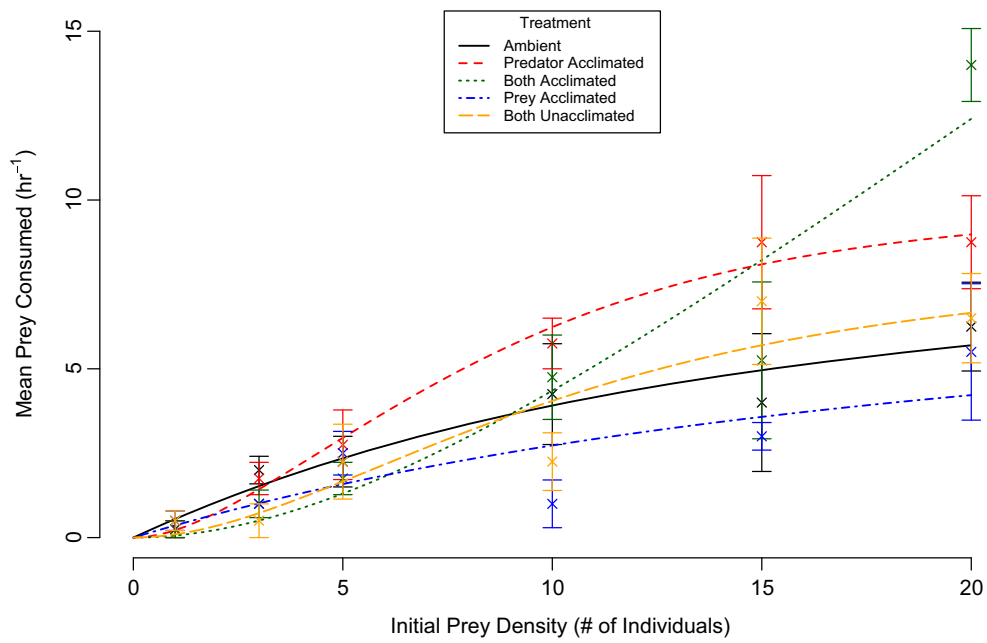


Fig. 5 LOWESS lines fitted to the proportion of prey consumed at each density per treatment

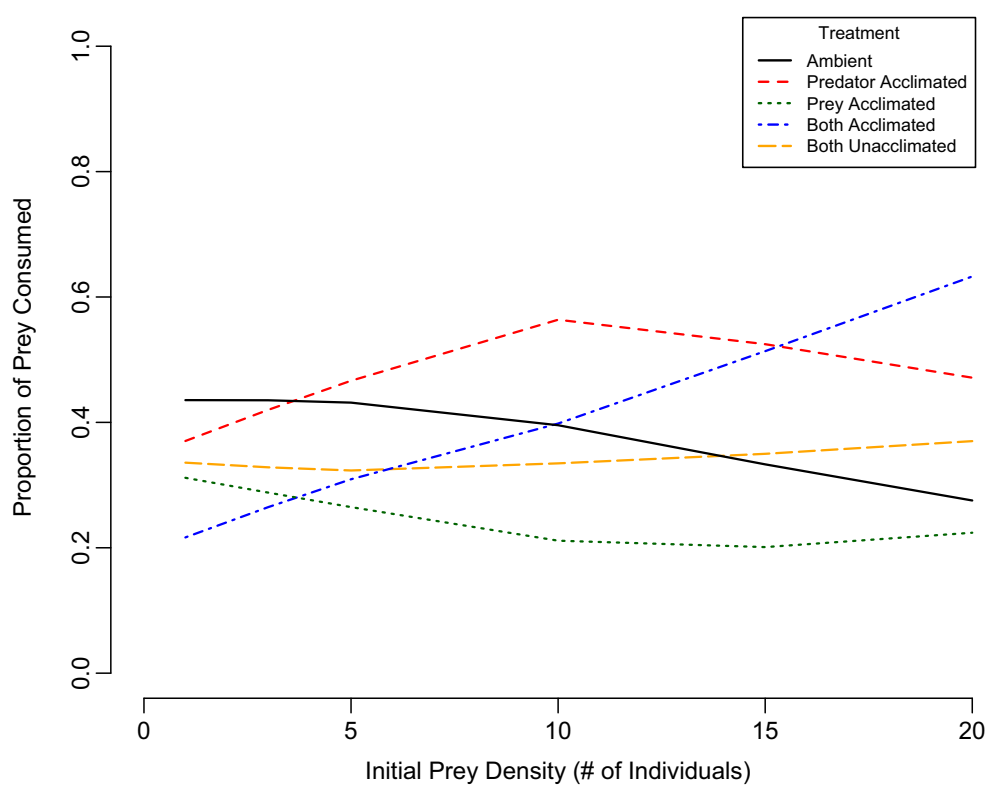

increasing temperatures (Jeschke et al. 2002). This produces a complex picture, wherein, the attack rate is high at low prey densities under current temperatures which could manifest as destabilising for prey populations. Warming may mitigate the risk for low density prey populations due to the change in Functional Response Type to the stabilising Type III under raised temperatures. Nonetheless, there was a higher maximum feeding rate at the raised temperature treatment which suggests that despite a change in resource consumption with regards to resource density, the end result remains that consumption increases due to temperature increase as a result of shorter handling time.

Attack rate signifies the instantaneous rate of successful search (Holling 1959) and determines the initial increase of consumption at low resource density. When the predator was non-acclimated the attack rate was higher towards acclimated prey. This may be due to the temperature rise increasing the metabolism of the prey and causing a consequent increase in prey velocity and increased boldness (van Baalen et al. 2001; Nowicki et al. 2012). As a result, more stimuli are provided to the predator and the encounter rate is increased, leading to a higher attack rate when the prey is acclimated (Curio 1976; Taylor 1984). However, when the predator was acclimated the attack rate was higher toward nonacclimated prey and lower toward prey that were acclimated. This suggests that acclimation to temperature may dampen attack rate in juvenile lesser-spotted dogfish and thus negate the effects of increased prey stimuli.
Handling time relates to the time taken to eat and digest prey items (Jeschke et al. 2002). Unfortunately, we cannot discuss the handling times of the treatments "Predator Acclimated", and "Both Unacclimated" with conviction, due to the non-significant logistic regression and GLM first and second order terms. Nonetheless, we can speculate from the results accumulated that at higher prey densities there may be further differences in resource consumption and, thus, handling times, as the motivational state changes (Englund et al. 2011). When the predator was non-acclimated the handling time was longer towards prey that were acclimated. This demonstrates that prey acclimation to temperature has a large effect on the handling of the prey possibly due to a mismatch in swimming speed of predator and the prey, and digestion speed in the predator (Dell et al. 2011). When the predator was acclimated the handling time was longer towards prey that were non-acclimated. This may again be related back to encounter rate (Curio 1976; Taylor 1984) and an increased metabolism and digestion speed due to acclimation of the predator (Dell et al. 2011). Therefore, when predator and prey are both acclimated to the same temperature there is a decrease in handling time which implies that consumption rates will also increase with temperature warming. While the effects of oxygen concentration were not tested in the present study, air was bubbled through all arenas during the treatments. Oxygen is a respiratory limiting factor at high temperatures and this effect is increased during acute warming scenarios, wherein there is no 
acclimation as organisms consume more oxygen when exposed to an abrupt temperature change than after an acclimation period (Bullock 1955; Kitching 1977).

Maximum feeding rate estimations are derived from functional response handling times (Juliano 2001). When the predator was non-acclimated the maximum feeding rate did not change with prey treatment but when the predator was acclimated the maximum feeding rate was far higher when prey were also acclimated. This indicates that when predator and prey populations undergo simultaneous acclimation to higher temperatures there will be a large increase in resource consumption, presumably due to the temperature mediation of the processes associated with handling time. When considered with the functional response types, it seems that simultaneous heating and acclimation produce an additive affect, which increases the maximum feeding rate and predator impact when prey is at 'high' densities. Although this must be caveated with the unreliable handling estimates of "Predator Acclimated", and "Both Unacclimated" which could be revealed under further investigation to have higher maximum feeding estimates.

There was a high variability in the shape of functional response in the different treatments with, justifiably, all three categorical functional responses observed. However, Type I functional responses require simultaneous handling and digestion and thus are only reported definitively amongst filter feeders (Lehman 1976; Jeschke et al. 2002; Jeschke et al. 2004). The intermediate response that was modeled is likely due to the low densities of prey supplied during the treatments (Jeschke et al. 2004), or the lack of habitat complexity in the experimental arena reducing handling limitations. As such, the results indicating Type I boundary responses may not directly reflect feeding ecology in the wild, but in this case serve as a comparison between the relative differences in parameter values. The results obtained were modeled as Type III responses due to the difference in proportional consumption. A Type III functional response was prevalent in trials at temperature apart from "Prey Acclimated". The change from Type II to Type III is concordant with other studies using fish predators which report shifts with environmental changes (Koski and Johnson 2002; Alexander et al. 2012), but contrasts with Wasserman et al. (2016b), which observed no functional response change in an invertebrate predator - prey system over various temperatures and habitat complexity. The Type III response when both were acclimated may be accounted for by the increased movement at high temperature (Biro et al. 2010) causing low consumption at low resource densities, but as the prey density increases there is a higher encounter rate and thus higher consumption. Furthermore, it is considered that when mortality is independent of foraging, foraging activity should increase concomitantly with resource availability (McNamara and Houston 1994). This would be the case when related to $S$. canicula in the Irish Sea where they are under low predation pressure. "Both Acclimated" had the highest magnitude functional response, while "Prey Acclimated" had the lowest. As "Prey Acclimated" functional response intensity was less than "Ambient" it suggests that the effect of temperature acclimation on E. marinus is more profound than on the predator, potentially because of the small body size of E. marinus giving the prey a metabolic advantage as the increased metabolic demands are mitigated by the small body size compared to the larger predator (Lincoln 1979; Whiteley et al. 2011; Reuman et al. 2014; Di Santo and Lobel 2016).

The combined additive effects of predator and prey acclimation appear to increase predator impact, while temperature increase drives a shorter handling time despite reducing the attack rate. While the present study deals specifically with juvenile lesser-spotted dogfish the results remain informative of the changes that temperature exerts on predation. This could have implications on the impacts of wild populations of $S$. canicula as they show spatial segregation by sex, temporal segregation and varying thermal strategies (Sims et al. 2001) as this may mediate the predation impacts when moving between thermally varied micro-climates. It is considered that when functional response is delivered as a phenomenological tool, the focus shifts from the shape of the response to the relative differences in parameter estimates (Lehman 1976; Jeschke et al. 2002; Alexander et al. 2012). This is due, in part, to the laboratory set up being inherently dissimilar to the conditions in sitú with regards to variation in temperature, prey availability, arena size, lack of refugia and habitat complexity. Nonetheless, we have provided a useful parameterization of the differences in resource consumption when predator and prey are factorially exposed to temperature increase.

This study demonstrates the importance of temperature as a regulating driver of predation. Temperature has the ability to increase predation pressure. Due to the high densities of Scyliorhinus canicula (Richardson 2016), increasing population size (Richardson 2016), and high discard survival rate (Revill et al. 2005), there is 
likelihood that predation on important fisheries species will increase. However, due to the generalist feeding strategy (Murdoch 1969) and patchy spatial distribution of prey, the Type III response is likely to prevail in the field (Trenkel et al. 2004).

Furthermore, Echinogammarus marinus may have an evolutionary advantage, due to body size, at higher temperatures (Genner et al. 2010; Di Santo and Lobel 2016), yet this may be mitigated when prey is found in high densities. The rate of warming, and subsequently environmental variation, affects maximum feeding estimates; consequently variation from the mean temperature is likely to have an impact upon predation pressure (Dell et al. 2011; Paaijmans et al. 2013; Vasseur et al. 2014). Furthermore, patchiness of prey populations could confer a benefit against predation, despite increased predation pressured conferred through decreased handling time. Though, it is necessary to caveat with the emphasis that thermal responses are species specific (Helmuth et al. 2002; Broitman et al. 2009; Englund et al. 2011), as is the "environment" that each species experiences (Kearney 2006; Broitman et al. 2009), but also highly variable between individuals (Spicer and Gaston 1999; Calosi et al. 2013).

It is important to understand and quantify interaction strength in food webs and the how changes in abiotic context will affect predator-prey dynamics with regards to species and individual levels within a system (Calosi et al. 2013). The functional responses and associated parameters shown here demonstrate the differential responses within two organisms to a range of climatic scenarios. This will have implications for the sustainability of fisheries in the Irish and Celtic Seas, wherein there is high abundance of Scyliorhinus canicula, as acclimation to increased temperature increases maximum feeding rate but changes the proportional consumption of sparse prey populations.

Acknowledgments We thank E. Gorman and B. McNamara for their technical support and assistance with animal maintenance, and D. Barrios-O'Neill for his help in stimulating discussion. We thank the anonymous reviewers for their constructive comments. This research was funded by the Department of Agriculture, Environment and Rural Affairs (Northern Ireland).

\section{Compliance with ethical standards}

Ethics statement All applicable international, national and/or institutional guidelines for the care and use of animals were followed.
Open Access This article is distributed under the terms of the Creative Commons Attribution 4.0 International License (http:// creativecommons.org/licenses/by/4.0/), which permits unrestricted use, distribution, and reproduction in any medium, provided you give appropriate credit to the original author(s) and the source, provide a link to the Creative Commons license, and indicate if changes were made.

\section{References}

AFBI (2016) Agri-Food and Biosciences data base web page: http://www.afbini.gov.uk/index/services/services-specialistadvice/coastal-science/coastal-monitoring/monitored-sites/sstrangford.htm

Alexander ME, Dick JTA, O'Connor N, Haddaway NR, Farnsworth K (2012) Functional responses of the intertidal amphipod Echinogammarus Marinus: effects of prey supply, model selection and habitat complexity. Mar Ecol Prog Ser. doi:10.3354/meps09978

Alexander ME, Dick JTA, O'Connor NE (2013) Trait-mediated indirect interactions in a marine intertidal system as quantified by functional responses. Oikos 122:1521-1531. doi:10.1111/j.1600-0706.2013.00472.x

Alexander ME, Kaiser H, Weyl OLF, Dick JTA (2015) Habitat simplification increases the impact of a freshwater invasive fish. Environ Biol Fish 98(2):477-486. doi:10.1007/s10641-014-0278-z

Ali M, Nicieza A, Wootton RJ (2003) Compensatory growth in fishes: a response to growth depression. Fish Fish 4(2):147190. doi:10.1046/j.1467-2979.2003.00120.x

Ariyomo TO, Watt PJ (2015) Effect of hunger level and time of day on boldness and aggression in the zebrafish Danio rerio. J Fish Biol 86(6):1852-1859. doi:10.1111/jfb.12674

Arrhenius S (1889) On the reaction velocity of the inversion of cane sugar by acids. Z Phys Chem 4(226-248): 24

Barrios-O'Neill D, Dick JTA, Emmerson MC, Ricciardi A, MacIsaac HJ (2015) Predator-free space, functional responses and biological invasions. Funct Ecol 29(3):377384. doi:10.1111/1365-2435.12347

Berlow EL, Dunne JA, Martinez ND, Stark PB, Williams RJ, Brose U (2009) Simple prediction of interaction strengths in complex food webs. PNAS 106:187-191

Biro PA, Beckmann C, Stamps JA (2010) Small within-day increases in temperature affects boldness and alters personality in coral reef fish. Proc Biol Sci 277:71-77

Bolker BM (2008) emdbook: ecological models and data in $R$. Princeton University press, Princeton, New Jersey, USA

Bolker BM (2010) Bbmle: tools for general maximum likelihood estimation. R Package. http://www.cran.rproject.org/

Bollache L, Dick JTA, Farnsworth KD, Montgomery WI (2008) Comparison of the functional responses of invasive and native amphipods. Biol Lett 4(2):166-169. doi:10.1098/rsbl.2007.0554

Broitman BR, Szathmary PL, Mislan KAS, Blanchette CA, Helmuth B (2009) Predator-prey interactions under climate change: the importance of habitat vs body temperature. Oikos 118(2):219-224. doi:10.1111/j.1600-0706.2008.17075.x

Brown JH, Gillooly JF, Allen AP, Savage VM, West GB (2004) Toward a metabolic theory of ecology. Ecology 85:1771-1789 
Bullock TH (1955) Compendation for temperature in the metabolism and activity of poikilotherms. Biol Rev 30:311-342

Cahill A, Aiello-Lammens M, Fisher-Reid M, Hua X, Karanewsky C, Ryu H, Sbeglia G, Spagnolo F, Waldron J, Warsi O, Wiens J (2013) How does climate change cause extinction? Proc Biol Sci/The Royal Society 280:20121890

Calosi P, Turner LM, Hawkins M, Bertolini C, Nightingale G, Truebano M, Spicer JI (2013) Multiple physiological responses to multiple environmental challenges: an individual approach. Integr Comp Biol 53(4):660-670. doi:10.1093/icb/ict041

Clark CW, Mangel M (2000) Dynamic state variable models in ecology: methods and applications. Oxford University Press, New York

Clusella-Trullas S, Blackburn TM, Chown SL (2011) Climatic predictors of tempera- ture performance curve parameters in ectotherms imply complex responses to climate change. Am Nat 177:738-751

Curio E (1976) The ethology of predation. Springer, Berlin, Germany

Dell AI, Pawar S, Savage VM (2011) Systematic variation in the temperature dependence of physiological and ecological traits. Proc Natl Acad Sci 108(26):10591-10596. doi:10.1073/pnas.1015178108

Dell AI, Pawar S, Savage VM (2014) Temperature dependence of trophic interactions are driven by asymmetry of species responses and foraging strategy. J Anim Ecol 83(1):70-84. doi:10.1111/1365-2656.12081

Di Santo V, Lobel PS (2016) Size affects digestive responses to increasing temperature in fishes: physiological implications of being small under climate change. Mar Ecol 37(4):813820. doi: $10.1111 /$ maec. 12358

Dick JTA, Johnson M, McCambridge S, Johnson J, Carson V, Kelly D, MacNeil C (2005) Predatory nature of littoral amphipod Echinogammarus Marinus: gut contents analysis and effects of alternative food and substrate heterogeneity. Mar Ecol Prog Ser 291:151-158. doi:10.3354/meps291151

Dick JTA, Gallagher K, Avlijas S, Clarke HC, Lewis SE, Leung S, Minchin D, Caffrey J, Alexander ME, Maguire C, Harrod C, Reid N, Haddaway NR, Farnsworth KD, Penk M, Ricciardi A (2013) Ecological impacts of an invasive predator explained and predicted by comparative functional responses. Biol Invasions 15:837-846

Dick JTA, Alexander ME, Jeschke JM, Ricciardi A, MacIsaac HJ, Robinson TB et al (2014) Advancing impact prediction and hypothesis testing in invasion ecology using a comparative functional response approach. Biol Invasions 16:735-753

Dick JTA, Laverty C, Lennon JJ, Barrios-O’Neill D, Mensink PJ, Britton JR, Medoc V, Boets P, Alexander ME, Taylor NG, Dunn AM, Hatcher MJ, Rosewarne PJ, Crookes S, MacIsaac HJ, Xu M, Ricciardi A, Wasserman RJ, Ellender BR, Weyl OLF, Lucy FE, Banks PB, Dodd JA, MacNeil C, Penk MR, Aldridge DC, Caffrey JM (2017) Invader relative impact potential: a new metric to understand and predict the ecological impacts of existing, emerging and future invasive alien species. J Appl Ecol. doi:10.1111/1365-2664.12849

Domi N, Bouquegneau JM, Das K (2005) Feeding ecology of five commercial shark species of the Celtic Sea through stable isotope and trace metal analysis. Mar Environ Res 60(5): 551-569. doi:10.1016/j.marenvres.2005.03.001

Duffy JE, Harvilicz AM (2001) Species-specific impacts of grazing amphipods in an eelgrass-bed community. Mar Ecol Prog Ser 223:201-211
Duffy JE, Hay ME (2000) Strong impacts of grazing amphipods on the organisation of a benthic community. Ecol Monogr 70: 237-263

Easterling DR, Horton B, Jones PD, Peterson TC, Karl TR, Parker DE, Salinger MJ, Razuvayev V, Plummer N, Jamason P, Folland CK (1997) Maximum and minimum temperature trends for the globe. Science 277:364-367

Easterling DR, Meehl GA, Parmesan C, Changnon SA, Karl TR, Mearns LO (2000) Climate extremes: observations, modelling, and impacts. Science 289:2068-2074

Ellis JR, Shackley SE (1997) The reproductive biology of Scyliorhinus canicula in the Bristol Channel, U.K. J Fish Biol 51(2):361-372

Englund G, Ohlund G, Hein CL, Diehl S (2011) Temperature dependence of the functional response. Ecol Lett 14(9): 914-921. doi:10.1111/j.1461-0248.2011.01661.x

Ferner M, Smee D, Weissburg M (2009) Habitat complexity alters lethal and non-lethal olfactory interactions between predators and prey. Mar Ecol Prog Ser. doi:10.3354/meps07764

Genner MJ, Sims DW, Southward AJ, Budd GC, Masterson P, McHugh M, Rendle P, Southall EJ, Wearmouth VJ, Hawkins S (2010) Body size-dependent responses of a marine fish assemblage to climate change and fishing over a century-long scale. Glob Chang Biol 16(2):517-527. doi:10.1111/j.13652486.2009.02027.x

Gilbert B, Tunney TD, McCann KS, DeLong JP, Vasseur DA, Savage V et al (2014) A bioenergetic framework for the temperature dependence of trophic interactions. Ecol Lett 17(8):902-914. doi:10.1111/ele.12307

Grigaltchik VS, Ward JW, Seebacher F (2012) Thermal acclimation of interactions: differential responses to temperature change alter predator-prey relationship. Proc R Soc B Biol Sci 279(1744):4058-4064. doi:10.1098/rspb.2012.1277

Haddaway NR, Wilcox RH, Heptonstall RE, Griffiths HM, Mortimer RJG, Christmas M, Dunn AM (2012) Predatory functional response and prey choice identify predation differences between native/invasive and parasitised/unparasitised crayfish. PLoS One 7(2):e32229. doi:10.1371/journal.pone.0032229

Helmuth B, Harley CDG, Halpin PM, O’Donnell M, Hofmann GE, Blanchette CA (2002) Climate change and latitudinal patterns of intertidal thermal stress. Science 298:1015-1017

Holling CS (1959) Some characteristics of simple types of predation and parasitism. Can Entomol 91:385-398

Huey RB, Berrigan D, Gilchrist GW, Herron JC (1999) Testing the adaptive significance of acclimation: a strong inference approach. Am Zool 39:323-336

Iacarella JC, Dick JTA, Alexander ME, Ricciardi A (2015) Ecological impacts of invasive alien species along temperature gradients: testing the role of environmental matching. Ecol Appl 25(3):706-716. doi:10.1890/14-0545.1

Jeschke JM, Kopp M, Tollrian R (2002) Predator functional responses: discriminating between handling and digesting prey. Ecol Monogr 72(1):95-112

Jeschke JM, Kopp M, Tollrian R (2004) Consumer-food systems: why type I functional responses are exclusive to filter feeders. Biol Rev Camb Philos Soc, 79(2), 337-349. Retrieved from http://www.ncbi.nlm.nih.gov/pubmed/15191227

Juliano SA (2001) Nonlinear curve fitting: predation and functional response curves. In: Scheiner SM, Gurevitch J (eds) Design and analysis of ecological experiments. Oxford University Press, Oxford, pp 178-196 
Kaiser MJ, Spencer BE (1994) Fish scavenging behaviour in recently trawled areas. Mar Ecol Prog Ser 112:41-49

Kearney M (2006) Habitat, environment and niche: what are we modeling? Oikos 115:186-191

Kitching RL (1977) Time resources and population dynamics in insects. Austral Ecol 2(1):31-42. doi:10.1111/j.14429993.1977.tb01125.x

Koski ML, Johnson BM (2002) Functional response of kokanee salmon (Oncorhynchus Nerka) to daphnia at different light levels. Can J Fish Aquat Sci 59:707-716. doi:10.1139/F02-045

Lang B, Rall BC, Brose U (2012) Warming effects on consumption and intraspecific interference competition depend on predator metabolism. J Anim Ecol. doi:10.1111/j.13652656.2011.01931.x

Laverty C, Dick JTA, Alexander ME, Lucy FE (2014) Differential ecological impacts of invader and native predatory freshwater amphipods under environmental change are revealed by comparative functional responses. Biol Invasions. doi:10.1007/s10530-014-0832-9

Le Quesne WJF, Pinnegar JK (2011) The potential impacts of ocean acidification: scaling from physiology to fisheries. Fish Fish. doi:10.1111/j.1467-2979.2011.00423.x

Lehman JT (1976) The filter-feeder as an optimal forager, and the predicted shapes of feeding curves. Limnol Oceanogr 21(4): 501-516. doi:10.4319/1o.1976.21.4.0501

Leite N, Guerra A, Almeida A, Marques JC, Martins I (2014) Long term variation of an amphipod species' population secondary production as indicator of incomplete resilience in a temperate estuary. Ecol Indic 36:324-333. doi:10.1016/j. ecolind.2013.08.001

Lincoln RJ (1979) British marine Amphipoda: Gammaridea. British Museum, London

MacNeil C, Dick JTA, Johnson MP, Hatcher MJ, Dunn AM (2004) A species invasion mediated through habitat structure, intraguild predation, and parasitism. Limnol Oceanogr 49(5): 1848-1856. doi:10.4319/lo.2004.49.5.1848

McNamara JM, Houston AI (1994) The effect of a change in foraging options on intake rate and predation rate. Am Nat 144:978-1000

Murdoch WW (1969) Switching in general predators: experiments on predator specificity and stability of prey populations. Ecol Monogr 39(4):335-354. doi:10.2307/1942352

Múrias T, Cabral JA, Marques JC (1996) Goss-custard JD (1996) short-term effects of intertidal macroalgal blooms on the microhabitat selection and feeding behaviour of wading birds in the Mondego estuary (west Portugal). Estuar Coast Shelf Sci 43:677-688

Nowicki JP, Miller GM, Munday PL (2012) Interactive effects of elevated temperature and $\mathrm{CO} 2$ on foraging behavior of juvenile coral reef fish. J Exp Mar Biol Ecol 412:46-51. doi:10.1016/j.jembe. 2011.10.020

Oaten A, Murdoch WW (1975) Functional response and stability in predator-prey systems. Am Nat 109(967):289-298. doi: $10.1086 / 282998$

Paaijmans KP, Heinig RL, Seliga RA, Blanford JI, Blanford S, Murdock CC, Thomas MB (2013) Temperature variation makes ectotherms more sensitive to climate change. Glob Chang Biol 19(8):2373-2380. doi:10.1111/gcb.12240

Paterson RA, Dick JTA, Pritchard DW, Ennis M, Hatcher MJ, Dunn AM (2015) Predicting invasive species impacts: a community module functional response approach reveals context dependencies. J Anim Ecol 84(2):453-463. doi:10.1111/1365-2656.12292

Peck LS, Clark MS, Morley SA, Massey A, Rossetti H (2009) Animal temperature limits and ecological relevance: effects of size, activity and rates of change. Funct Ecol 23(2):248256. doi:10.1111/j.1365-2435.2008.01537.x

Pörtner HO, Knust R (2007) Climate change affects marine fishes through the oxygen limitation of thermal tolerance. Science (New York, N.Y.), 315(5808), 95-7. doi:10.1126/science. 1135471

Pritchard DW (2014) frair: Functional response analysis in R. R package version 0.4

Pritchard DW, Paterson RA, Bovy HC, Barrios-O'Neill D (2017) Frair: an R package for fitting and comparing consumer functional responses. Methods Ecol Evol. doi:10.1111/2041-210X.12784

R Development Core Team (2015) R: A Language and Environment for Statistical Computing. R Foundation for Statistical Computing, Vienna, Austria. ISBN 3-90005107-0, URL http:/www.R-project.org

Rall BC, Vucic-Pestic O, Ehnes RB, Emmerson M, Brose U (2010) Temperature, predator-prey interaction strength and population stability. Glob Chang Biol 16(8):2145-2157. doi:10.1111/j.1365-2486.2009.02124.x

Rall BC, Brose U, Hartvig M, Kalinkat G, Schwarzmüller F, VucicPestic O, Petchey OL (2012) Universal temperature and bodymass scaling of feeding rates. Philos Trans R Soc Lond Ser B Biol Sci 367(1605):2923-2934. doi:10.1098/rstb.2012.0242

Real LA (1977) The kinetics of functional response. Am Nat 111: 289-299. doi:10.1086/283161

Reuman DC, Holt RD, Yvon-Durocher G (2014) A metabolic perspective on competition and body size reductions with warming. J Anim Ecol 83(1):59-69. doi:10.1111/1365-2656.12064

Revill AS, Dulvy N, Holst R (2005) The survival of discarded lesser-spotted dogfish (Scyliorhinus Canicula) in the western English Channel beam trawl fishery. Fish Res 71:121-124

Richardson L (2016) UK Sea fisheries statistics 2015. 1st ed. London: Marine Management Organisation, 2016. [Accessed on:17/11/2016]

Rogers D (1972) Random search and insect population models. J Anim Ecol 41:369-383

Savage VM, Gillooly JF, Brown JH, West GB, Charnov EL (2004) Effects of body size and temperature on population growth. Am Nat 163:429-441

Sguotti C, Lynam CP, García-Carreras B, Ellis JR, Engelhard GH (2016) Distribution of skates and sharks in the North Sea: 112 years of change. Glob Chang Biol 22(8):2729-2743. doi: $10.1111 / \mathrm{gcb} .13316$

Sims DW (1996) The effect of body size on the standard metabolic rate of the lesser spotted dogfish. J Fish Biol 48(3):542-544. doi:10.1111/j.1095-8649.1996.tb01447.x

Sims DW (2003) Tractable models for testing theories about natural strategies: foraging behaviour and habitat selection of free-ranging sharks. J Fish Biol 63(s1):53-73. doi:10.1111/j.1095-8649.2003.00207.x

Sims DW, Nash J, Morritt D (2001) Movements and activity of male and female dogfish in a tidal sea lough: alternative behavioural strategies and apparent sexual segregation. Mar Biol 139(6):1165-1175. doi:10.1007/s002270100666 
Smout S, Asseburg C, Matthiopoulos J, Fernández C, Redpath S, Thirgood S, Harwood J (2010) The functional response of a generalist predator. PLoS One 5. doi:10.1371/journal.pone.0010761

Sokolov AP, Stone PH, Forest CE, Prinn R, Sarofim MC, Webster $M$ et al (2009) Probabilistic forecast for twenty-first-century climate based on uncertainties in emissions (without policy) and climate parameters. J Clim 22(19):5175-5204. doi:10.1175/2009JCLI2863.1

Solomon ME (1949) The natural control of animal popula- tions. J Anim Ecol 18:1-35

Spicer JI, Gaston KJ (1999) Physiological diversity and its ecological implications. Blackwell Science, Oxford, UK

Stevnbak K, Scherber C, Gladbach DJ, Beier C, Mikkelsen TN, Christensen S (2012) Interactions between aboveand belowground organisms modified in climate change experiments. Nat Clim Chang 2(11):805-808. doi:10.1038/nclimate1544

Taylor R (1984) Predation. Chapman \& Holl, New York

Terblanche JS, Nyamukondiwa C, Kleynhans E (2010) Thermal variability alters climatic stress resistance and plastic responses in a globally invasive pest, the Mediterranean fruit fly (Ceratitis Capitata). Entomol Exp Appl 137:304-315. doi:10.1111/j.1570-7458.2010.01067.x

Trenkel VM, Pinnegar JK, Blanchard JL, Tidd AN (2004) Can multispecies models be expected to provide better assessments for Celtic Sea groundfish stocks? ICES Annual Science Conference, Vigo. Int Counc Explor Sea Comm Meet 2004/FF:05

van Baalen M, Krrivan V, van Rijn PCJ, Sabelis MW (2001) Alternative food, switching predators, and the persistence of predator-prey systems. Am Nat 157(5):512-524. doi:10.1086/319933

Van Slyke DD, White GF (1911) Digestion of protein in the stomach and in the intestine of the dogfish. J Biol Chem 9:209-217
Vasseur DA, DeLong JP, Gilbert B, Greig HS, Harley CDG, McCann KS et al (2014) Increased temperature variation poses a greater risk to species than climate warming. Proc. Biol Sci / The Royal Society 281(1779):20132612. doi:10.1098/rspb.2013.2612

Vucic-Pestic O, Rall BC, Kalinkat G, Brose U (2010) Allometric functional response model: body masses constrain interaction strengths. Journal of Animal Ecology, 79:249-256. doi:10.1111/j.1365-2656.2009.01622.x

Wasserman RJ, Alexander ME, Dalu T, Ellender BR, Kaiser H, Weyl OLF (2016a) Using functional responses to quantify interaction effects among predators. Functional Ecology. doi:10.1111/1365-2435.12682

Wasserman RJ, Alexander ME, Weyl OLF, Barrios-O'Neill D, Froneman PW, Dalu T (2016b) Emergent effects of structural complexity and temperature on predator-prey interactions. Ecosphere, 7(2). doi:10.1002/ecs2.1239

Whiteley NM, Rastrick SPS, Lunt DH, Rock J (2011) Latitudinal variations in the physiology of marine gammarid amphipods. Journal of Experimental Marine Biology and Ecology, 400(1):70-77. doi:10.1016/j.jembe.2011.02.027

Woodward G, Benstead JP, Beveridge OS, Blanchard J, Brey T, Brown LE, Cross WF, Friberg N, Ings TC, Jacob U, Jennings S, Ledger ME, Milner AM, Montoya JM, O' Gorman EJ, Olesen JM, Petchey OL, Pichler DE, Reuman DC, Thompson MSA, Van Veen FJF, Yvon-Durocher G (2010) Ecological networks in a changing climate. Advances in Ecological Research, 42, 71-138

Wootton RJ, Ali M (2001) Capacity for growth compensation in juvenile three-spined sticklebacks experiencing cycles of food deprivation. Journal of Fish Biology, 58: (6)15311544. doi::10.1111/j.1095-8649.2001.tb02310.x

Yocom TG, Edsall TA (1974) Effect of acclimation temperature and heat shock on vulnerability of fry of lake whitefish (Coregonus clupeaformis) to predation. J Fish Res Board Can 31:1503-1506 